\title{
Changes in the social behavior of urban animals: more aggression or tolerance?
}

\author{
Rafał Łopucki $^{1}$ (D) Daniel Klich ${ }^{2} \cdot$ Adam Kiersztyn $^{3}$
}

Received: 28 April 2020 / Accepted: 4 October 2020 / Published online: 23 October 2020

(c) The Author(s) 2020

\begin{abstract}
Behavioral traits play a major role in successful adaptation of wildlife to urban conditions. However, there are few studies showing how urban conditions affect the social behavior of urban animals during their direct encounters. It is generally believed that the higher density of urban populations translates into increased aggression between individuals. In this paper, using a camera-trap method, we compared the character of direct encounters in urban and non-urban populations of the striped field mouse Apodemus agrarius (Pallas, 1771), a species known as an urban adapter. We confirmed the thesis that urbanization affects the social behavior and urban and rural populations differ from each other. Urban animals are less likely to avoid close contact with each other and are more likely to show tolerant behavior. They also have a lower tendency towards monopolization of food resources. The behavior of urban animals varies depending on the time of day: in the daytime, animals are more vigilant and less tolerant than at night. Our results indicate that, in the case of the species studied, behavioral adaptation to urban life is based on increasing tolerance rather than aggression in social relations. However, the studied urban adapter retains the high plasticity of social behavior revealed even in the circadian cycle. The observation that tolerance rather than aggression may predominate in urban populations is a new finding, while most studies suggest an increase in aggression in urban animals. This opens an avenue for formulating new hypotheses regarding the social behavior of urban adapters.
\end{abstract}

Keywords Urbanization · Behavior · Adaptation · Mammals $\cdot$ Intra-population interactions $\cdot$ Escape behavior

\section{Introduction}

Wild terrestrial vertebrates under the pressure of urbanization are usually forced to use highly transformed and fragmented habitats and novel sources of food. They also have to interact with constant anthropogenic disturbances

Handling editor: Raquel Monclús.

Rafał Łopucki

lopucki@kul.pl

Daniel Klich

daniel_klich@sggw.pl

Adam Kiersztyn

adam.kiersztyn.pl@gmail.com

1 Centre for Interdisciplinary Research, The John Paul II Catholic University of Lublin, Konstantynów 1J, 20-708 Lublin, Poland

2 Department of Animal Genetics and Conservation, Warsaw University of Life Sciences-SGGW, Ciszewskiego 8, 02-786 Warsaw, Poland

3 Institute of Computer Science, Lublin University of Technology, Nadbystrzycka 36B, 20-618 Lublin, Poland and highly diverse stimuli and stressors, including vehicular traffic, human presence, pets, light pollution, and anthropogenic noise (Atwell et al. 2012; Swaddle et al. 2015; Weaver et al. 2019). Given such a diverse set of evolutionarily novel factors affecting animals, only some wild species are able to adapt to city life (McKinney 2008; Francis and Chadwick 2012). It has been shown that behavioral traits play a major role in successful adaptation of species to urban conditions (Lowry et al. 2013; Swaddle et al. 2015; Tryjanowski et al. 2016; Weaver et al. 2019).

A large number of studies on the behavior of urban vertebrates focus on their response to human presence, because many wild animals exhibit fear behavior towards humans (Fernández-Juricic and Schroeder 2003; Mikula et al 2018). For large and medium-sized mammals, e.g. bobcat Lynx 
rufus, coyote Canis latrans, mule deer Odocoileus hemionus or wild boar Sus scrofa, the most common behavioral response is to adjust the circadian rhythm to avoid people (George and Crooks 2006; Podgórski et al. 2013; Gaynor et al. 2018). In the case of birds or mammals whose daytime patterns of activity coincides with the human activity, the avoidance of people is not temporal but spatial and is based on keeping a safe distance in space (Atwell et al. 2012; Bateman and Fleming 2014; Cavalli et al. 2018; Mikula et al 2018; Uchida et al. 2019).

In addition to the reaction of wild vertebrates to human presence, their behavioral response to other elements of the urban habitat has been a frequent object of urban studies (Lowry et al. 2013). For example, it has been shown that the strong fragmentation of urban green areas causes changes in the spatial behavior of urban coachwhip snakes Masticophis flagellum (Mitrovich et al. 2009), bobcats (Tigas et al. 2002) or coyotes (Atwood and Weeks 2003). Changes in the preferences of nesting places, new food sources, and the impact of a new group of urban predators have been widely studied for many species of vertebrates, including reptiles, birds and mammals as well (Contesse et al. 2004; Møller 2012; Chavez-Zichinelli et al. 2013; Thomas et al. 2018; Aviles-Rodriguez and Kolbe 2019; Gallo et al. 2019; Palacio 2020). For urban birds, the impact of light and noise pollution on the behavior has also been shown (Moiron et al. 2015; Swaddle et al. 2015; Weaver et al. 2019). Various indicators were used to study these phenomena: from measurements of home ranges, risk-taking behavior, success in solving problems, escape response, diurnal activity, or aggression levels to more sophisticated indicators such as noise-dependent changes in vocalization, stress hormone levels, or genetic markers (e.g., Bonier 2012; Francis et al. 2015; Meillere et al. 2015; Moiron et al. 2015; Vincze et al. 2016; Santangelo et al. 2018; Schell et al. 2018; Łopucki et al. 2019; Solaro and Sarasola 2019).

However, there are very few studies showing how these individual behavioral traits (e.g., personality, stress level), population traits (e.g., higher densities, genetic variation), and habitat features (e.g. isolation of green areas, clumped distribution of anthropogenic food, human presence) affect the social behavior of urban animals during their direct encounters with conspecifics. In other words, relatively little attention has been paid to direct intra-population relationships between individuals in the urban environment, although increased frequency of such encounters and increased costs of social interactions in urban populations can be expected (Lacy and Martins 2003; Fokidis et al 2011; Baxter-Gilbert and Whiting 2019; Marty et al. 2019a). Given the gap in this knowledge, mutually exclusive hypotheses describing this aspect of social behavior of urban animals can be formulated. The first hypothesis may assume that direct contacts between urban individuals are characterized by higher aggressiveness than in non-urban populations (which seems to be consistent with papers of Lacy and Martins 2003; Fokidis et al 2011; Tuomainen and Candolin 2011; Møller 2012; Lowry et al. 2013; Miranda et al. 2013; del Barco-Trillo 2018; Baxter-Gilbert and Whiting 2019; Uchida et al. 2019). In turn, another hypothesis may assume that direct contacts between urban individuals are more tolerant compared to non-urban populations, since urban animals have access to anthropogenic food resources, and abundance of such food can reduce intra-population competition and the tendency towards monopolization of resources (Francis and Chadwick 2012; Oro et al. 2013; Becker and Hall 2014; Thomas et al. 2018 but see Marty et al 2019b).

The aim of this paper was to test which of the aforementioned hypotheses is best supported in the urban and non-urban population of the striped field mouse Apodemus agrarius (Pallas, 1771). Using a camera-trap method, we compared the character of the direct encounters between individuals in urban and rural areas. The investigated species is a good subject to study the impact of urbanization on the adaptive behavior of animals: striped field mice inhabit green areas in cities and is regarded as an urban adapter (Andrzejewski et al. 1978; Gortat et al. 2014), and simultaneously, are also common in rural areas (Lopucki et al. 2013, 2020).

\section{Methods}

\section{Study area}

The study was carried out in the city of Lublin (Poland, $51^{\circ} 15^{\prime} \mathrm{N} ; 22^{\circ} 33^{\prime} \mathrm{E}$, area $147.5 \mathrm{~km}^{2}$, population of 350,000 ) and its surrounding area, i.e. in an agricultural landscape within $15 \mathrm{~km}$ from the administrative boundaries of the city. In the city, data were collected in 15 green areas (urban sites) located in the central zone (Fig. 1). The location of the observation sites in the city center ensured a higher probability that the observed animals belong to a typical urban population. We selected green areas where small mammals could potentially occur (i.e. habitats with dense undergrowth or ground cover) and sites that allowed us to find a safe place to mount the camera-trap and conduct our observation undisturbed for at least $24 \mathrm{~h}$. Camera traps in urban sites were isolated from each other by distance or anthropogenic barriers (roads and/or buildings) to maximize the likelihood that the same animals are not visiting multiple traps.

In the surroundings of the city, data were collected in 18 locations (rural sites) on uncultivated patches with seminatural vegetation (grasses, herbaceous plants, and shrubs) surrounded by arable fields. To maximize the likelihood that the same animals are not visiting multiple traps, the distance 


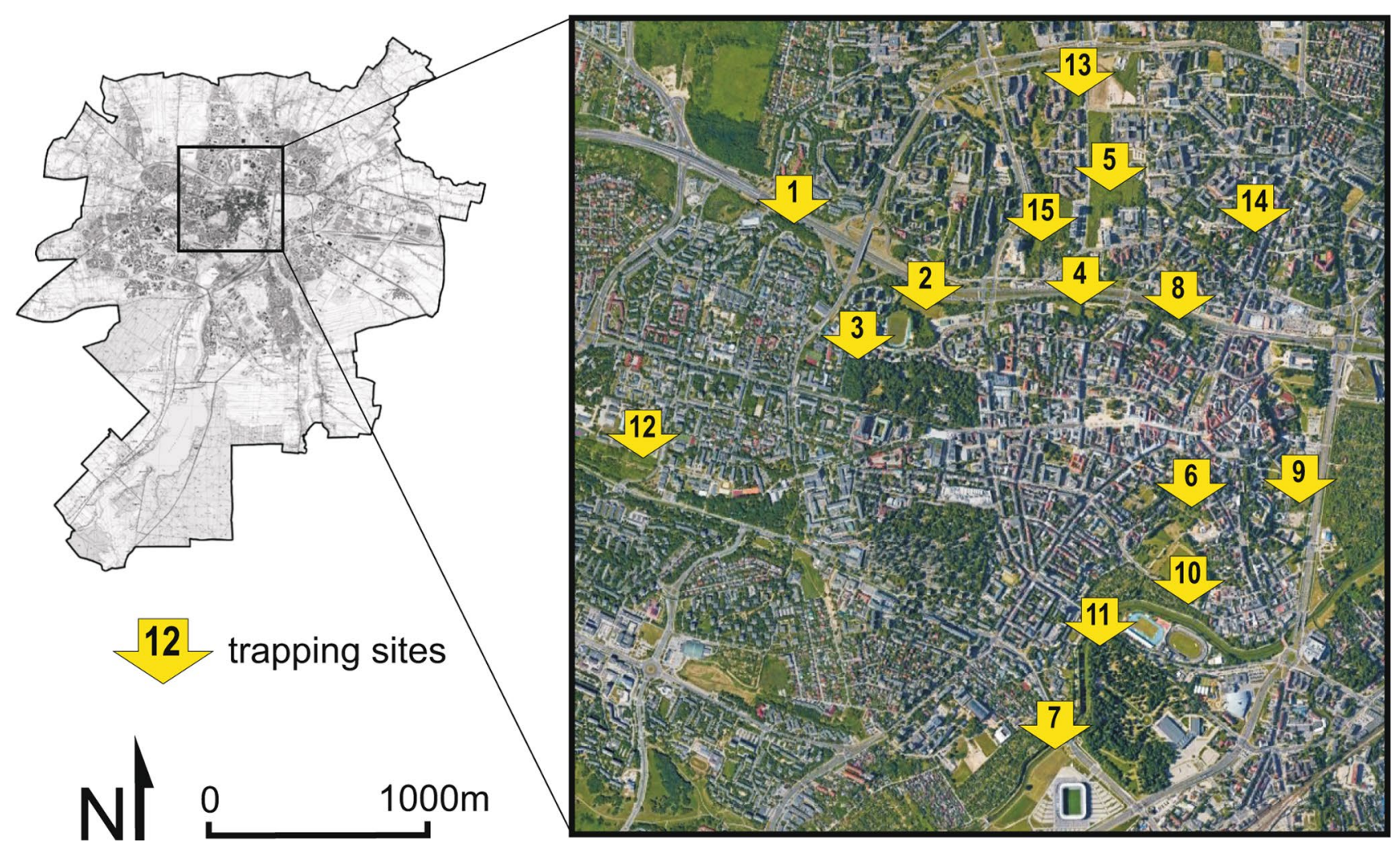

Fig. 1 Location of urban camera-trapping sites in the city of Lublin

between observation sites was over $1 \mathrm{~km}$. Arable land with scattered farmers' settlements is the dominant landscape type around Lublin. The observation sites placed in such a landscape had in their surroundings, apart from arable fields, also single rural buildings and local access roads.

\section{Camera-trap data collection}

Data on the intra-population behavior of A. agrarius were collected using a camera-trap method. Methodological challenges related to the study of small mammals using camera traps have recently been described by Łopucki and Kiersztyn (2020). In brief, these include: (1) due to the body size of small mammals, the camera trap must be placed close to the ground, preferably vertically oriented, and the camera sensors must cover only a small area to see and identify an animal, (2) due to the speed of movement of small mammals, different types of baits must usually be used to attract a small mammal to the monitored area and stop its movement for a while (e.g. for species identification), and (3) to minimize the effect of the bait (a habituation effect), observations should not be carried out for many days in the same site. Considering the issues presented above, in this work, we carried out our observation for only $24 \mathrm{~h}$ per site (each site was filmed for a single 24 -h period) and the down-facing camera trap with passive infrared sensors was placed about $80 \mathrm{~cm}$ above the ground (an approximate size of a camera's field of view was $0.3 \times 0.4 \mathrm{~m}$ ). About $100 \mathrm{~g}$ of bread attached to the ground was used as bait. The camera recorded a 60 -s video after the motion sensor was activated. The total time of observations (camera-trapping effort) was $792 \mathrm{~h}$, i.e. $360 \mathrm{~h}$ from 15 urban sites and $432 \mathrm{~h}$ from 18 rural sites.

The camera trapping was carried out in winter. We chose this time of year to conduct the research during the nonreproductive season, i.e. when all individuals in the population have the same reproductive status (Andrzejewski et al. 1978). This was important because the camera-trap method did not allow us to distinguish sex or reproductive status of the animals.

\section{Viewing recordings and classification of behaviors}

Recordings were screened and the time of the beginning and end of each animal visit with an accuracy of up to one second was noted. Moreover, when two individuals visited the trap site at the same time, their behavior towards each other was described and assigned to one of the three categories: (1) aggressive behavior - when at least one animal exhibited aggressive postures (attacking, biting, chasing, pursuit) and the encounter terminated with fleeing of one or both individuals; (2) avoidance behavior-when at least one animal ran away immediately after noticing that another individual was 
nearby in the trap site, and (3) tolerance behavior-when two individuals stayed together in the trap site, did not show aggressive behavior, and ate the bait together.

During the total camera-trapping time, the individuals of the studied species were observed for $75 \mathrm{~h} 58 \mathrm{~min}$ and $43 \mathrm{~s}$ in the urban areas and $49 \mathrm{~h} 26 \mathrm{~min}$ and $20 \mathrm{~s}$ in the rural areas. During this time, 1031 encounters between two striped field mice were noted (detailed information in Table 1). Besides the studied animals, other rodent species, mammalian predators, and birds appeared in some trap sites. These were e.g. the common vole Microtus arvalis, the bank vole Myodes glareolus, other species of the genus Apodemus (the yellownecked or wood mouse), the stone marten Martes foina, the cat Felis catus, the least weasel Mustela nivalis, the great tit Parus major, the Eurasian blue tit Cyanistes caeruleus, the Eurasian magpie Pica pica, and the Eurasian wren Troglodytes troglodytes. The observations of these species and their intraspecific or interspecific encounters were not analyzed in this work. The studied species was clearly distinguishable from the other species of small mammals by the characteristic dark stripe on the back.

\section{Data analysis}

During our study, we did not mark animals individually; hence, there was no possibility of individual identification.
Table 1 Study effort (time of camera trapping) and material obtained for particular study sites

\begin{tabular}{|c|c|c|c|}
\hline $\begin{array}{l}\text { Study site localization and } \\
\text { number }\end{array}$ & $\begin{array}{l}\text { Time of observa- } \\
\text { tion }[\mathrm{h}]\end{array}$ & $\begin{array}{l}\text { Total time when the studied species } \\
\text { was observed [h:min:s] }\end{array}$ & $\begin{array}{l}\text { No of encoun- } \\
\text { ters recorded }\end{array}$ \\
\hline Rural 1 & 24 & $0: 37: 33$ & 12 \\
\hline Rural 2 & 24 & $1: 23: 45$ & 12 \\
\hline Rural 3 & 24 & $1: 18: 45$ & 0 \\
\hline Rural 4 & 24 & $1: 22: 33$ & 0 \\
\hline Rural 5 & 24 & $0: 55: 12$ & 0 \\
\hline Rural 6 & 24 & 1:11:53 & 0 \\
\hline Rural 7 & 24 & $0: 55: 43$ & 0 \\
\hline Rural 8 & 24 & $0: 59: 16$ & 0 \\
\hline Rural 9 & 24 & $1: 22: 37$ & 0 \\
\hline Rural 10 & 24 & $1: 43: 27$ & 0 \\
\hline Rural 11 & 24 & $1: 42: 36$ & 1 \\
\hline Rural 12 & 24 & $2: 10: 36$ & 2 \\
\hline Rural 13 & 24 & $2: 11: 31$ & 0 \\
\hline Rural 14 & 24 & $5: 59: 14$ & 33 \\
\hline Rural 15 & 24 & $10: 47: 18$ & 130 \\
\hline Rural 16 & 24 & 9:54:41 & 64 \\
\hline Rural 17 & 24 & $2: 50: 24$ & 4 \\
\hline Rural 18 & 24 & $1: 59: 16$ & 4 \\
\hline Total for rural sites & 432 & $49: 26: 20$ & 262 \\
\hline Urban 1 & 24 & $3: 58: 25$ & 6 \\
\hline Urban 2 & 24 & $2: 24: 29$ & 1 \\
\hline Urban 3 & 24 & 0:44:08 & 0 \\
\hline Urban 4 & 24 & $4: 27: 36$ & 3 \\
\hline Urban 5 & 24 & 13:36:01 & 232 \\
\hline Urban 6 & 24 & 14:09:13 & 144 \\
\hline Urban 7 & 24 & 12:03:02 & 357 \\
\hline Urban 8 & 24 & $0: 58: 52$ & 4 \\
\hline Urban 9 & 24 & 2:30:01 & 2 \\
\hline Urban 10 & 24 & $2: 30: 48$ & 2 \\
\hline Urban 11 & 24 & $3: 10: 51$ & 2 \\
\hline Urban 12 & 24 & $3: 57: 17$ & 5 \\
\hline Urban 13 & 24 & $2: 34: 52$ & 6 \\
\hline Urban 14 & 24 & 3:08:05 & 2 \\
\hline Urban 15 & 24 & 5:45:03 & 3 \\
\hline Total for urban sites & 360 & $75: 58: 43$ & 769 \\
\hline
\end{tabular}


Similarly, we were not able to distinguish the sex or age of the recorded individuals. We assumed that all individuals were sexually inactive during the observations (the studies were conducted in winter) and the number of males and females did not differ significantly (based on literature data: Łopucki et al. 2013). Such limitations in data description were necessitated by the demands of urban research-it is difficult to carry out repeated live trapping, marking, and observations of rodents in publicly accessible green areas in the city centre, because such research activity arouses interest of onlookers and may result in disturbances in the experiment, vandalism, or theft of the camera traps. Due to these limitations, we did not mark the individuals and considered our material as a randomly collected pool of behavioral observations allowing general characterization of behavior dominating in urban or rural populations. To limit the possibility of repeated observations of the same individual, camera-trap sites were isolated from each other by distance or anthropogenic barriers, so that the same animals are not visiting multiple traps. The problem with the identification of individuals and independence of observation is a typical limitation of camera-trap studies, since many animals do not show clear individual differences and even sexual dimorphism. Therefore, individual marking adapted to the camera trapping method has been used in very few studies (Łopucki 2007; Sollmann 2018).

Assuming these restrictions, which applied to both urban and rural populations, we considered each encounter as an independent observation for which we were able to provide the following information: (1) time of occurrence of the encounter-based on sunrise and sunset over the period studied, we divided the encounters into daytime (7:00-15:59) and nighttime (16:00-6:59); (2) the duration of the encounter with an accuracy of one second; (3) behavior of the animals described using qualitative categories: aggression, tolerance, avoidance; (4) escape behavior of the individuals upon the encounter-we noted which individual was the first to escape from the observation point: the animal that appeared earlier (the first to find food) or the one that appeared later. In addition, using the average number of encounters in the study sites as a reference value (i.e., 31.2 encounters per site), we divided the sites into two groups in terms of the density of the rodents: a study site with the number of encounters $<31.2$ or $>31.2$ was assigned to a lowor high-density group, respectively (Table 1 ).

Due to the previously described limitations related to our data, we tested various modeling approach, including study site as random variable, which showed a convergence error due to too many random slopes. Finally, we adopted the simplest solution based on generalized linear models with a binary dependent variables. As a results, statistical analysis was carried out in two steps. First, the differences in the prevalence of a given type of behavior during the direct encounters in the urban and rural populations were analyzed. In this analysis, the probability of frequency of each type of behavior (aggression, avoidance, or tolerance) was estimated in three separate generalized linear models with binary dependent variables. The following data encoding was applied: while analyzing the frequency of aggressive behavior in a given population, we marked all encounters with aggression as " 1 " and other encounters (tolerance and avoidance) as "0". An analogous method was used for construction of models for tolerance and avoidance. In all these models, the following response variables were used: (a) "site and time of encounters" divided into three groups: urban population daytime encounters (Urban Day), urban population nighttime encounters (Urban Night), and rural population nighttime encounters (Rural Night) (there were no "rural population daytime encounters", because the rural rodents were not active during the day), (b) "rodent density in the study sites" divided into two groups: low density and high density, and (c) "duration of the encounter"-as a covariate.

In the second step of the analysis, we checked whether the escape behavior of the encountering individuals differ between the urban and rural populations. We built a model with a binary dependent variable, where escape of an individual that was the first to find the food was marked as " 1 ", and escape of the second individual was marked as "0". We did not use data describing cases of simultaneous escape of both encountering individuals, but such cases were very rare. In this model, the following response variables were used: (a) "site and time of encounters" and (b) "rodent density in study sites" (as above). The escape behavior was analyzed only for the aggressive and avoidance encounters, i.e. related to fighting in defense or for access to the resource (food).

To choose the best-fit model, we compared the models using the Akaike Information Criterion in the backward elimination procedure. Statistically significant variables in the model were compared using the least significant difference test (LSD). All statistical analyses were performed using SPSS software (version 24.0, IBM Corporation, Armonk, NY, USA).

\section{Results}

As can be seen in Table 1, our camera-trapping effort for the rural population was larger ( $432 \mathrm{~h}$ of observation) than for the urban population ( $360 \mathrm{~h}$ of observation). Nevertheless, larger material demonstrating the presence of A. agrarius in the observation sites (total time of observation of the species) was obtained for the urban than rural areas (75:58:43 and 49:26:20, respectively). Even greater disparities were found in the number of recorded encounters-769 in the 


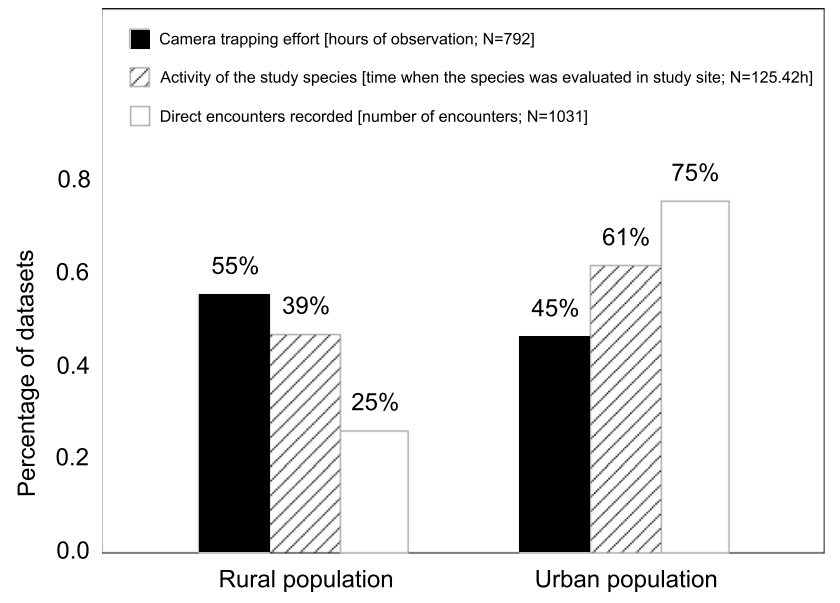

Fig. 2 Comparison of the urban and rural populations in terms of the camera-trapping effort, total time of observation of the species, and the number of recorded direct encounters

urban sites and 262 in the rural sites (Table 1). These differences are presented as percentage values in Fig. 2.

The encounters between the field stripped mice differed between the rural and urban populations, and the behavior of the rodent was dependent on the time of day. Significant differences between analyzed groups (Rural Night; Urban Day; Urban Night) were found in the case of tolerance and avoidance behavior (Table 2). The avoidance behavior was observed more rarely in Urban-Night group than RuralNight group ( $p=0.034$ ) (Fig. 3). The tolerance behavior was more common in Urban-Night group than Rural-Night group ( $p=0.002$ ) (Fig. 3). We found no statistically significant differences in the case of aggression (Fig. 3). In addition, significant differences were noted in the frequency of tolerance behavior in the urban population between the day and night ( $p=0.034$; Fig. 3 ).

The duration of the encounter was statistically significantly variable in the models $(p<0.000$ for all types of behavior, Table 2): the short encounter time meant avoidance or aggression, whereas the long encounter time was usually associated with tolerant behavior. The rodent density in the site explained the frequency of aggression and avoidance, but not tolerance behavior (Table 1).

In the model constructed for aggressive behavior, the interaction between the "site and time of encounter" and "rodent density in the site" was a statistically significant ( $p=0.012$; Table 2). However, regarding sites within the same density groups, the only significant difference was found between the rural population and the urban population
Table 2 Statistical summary of generalized linear models for aggression, avoidance, and tolerance behaviors and predictors: (a) site and time of encounters, (b) duration of the encounter, (c) rodent density in the site and interaction $(\mathrm{a}) \times(\mathrm{c})$

\begin{tabular}{|c|c|c|c|c|c|c|c|}
\hline \multirow[t]{2}{*}{ Source } & \multirow[t]{2}{*}{$d f$} & \multicolumn{2}{|c|}{ Aggression } & \multicolumn{2}{|c|}{ Avoidance } & \multicolumn{2}{|c|}{ Tolerance } \\
\hline & & Wald $\chi^{2}$ & $p$ & Wald $\chi^{2}$ & $p$ & Wald $\chi^{2}$ & $p$ \\
\hline Intercept & 1 & 14.987 & $0.000^{*}$ & 30.119 & $0.000 *$ & 459.655 & $0.000 *$ \\
\hline (a) Site and time of encounters & 2 & 3.695 & 0.158 & 7.878 & $0.020^{*}$ & 11.820 & $0.003 *$ \\
\hline (b) Duration of the encounter & 1 & 78.757 & $0.000^{*}$ & 106.798 & $0.000^{*}$ & 290.222 & $0.000^{*}$ \\
\hline (c) Rodent density in the site & 1 & 10.291 & $0.001 *$ & 11.222 & $0.001 *$ & - & \\
\hline Interaction $(a) \times(c)$ & 2 & 8.924 & $0.012^{*}$ & 5.484 & 0.064 & - & \\
\hline
\end{tabular}

All models were statistically significant (for aggression: $\chi^{2}=187.9, d f=6, p=0.000$, for avoidance: $\chi^{2}=473.3 d f=6, p=0.000$, for tolerance: $\left.\chi^{2}=923.8, d f=3, p=0.000\right)$
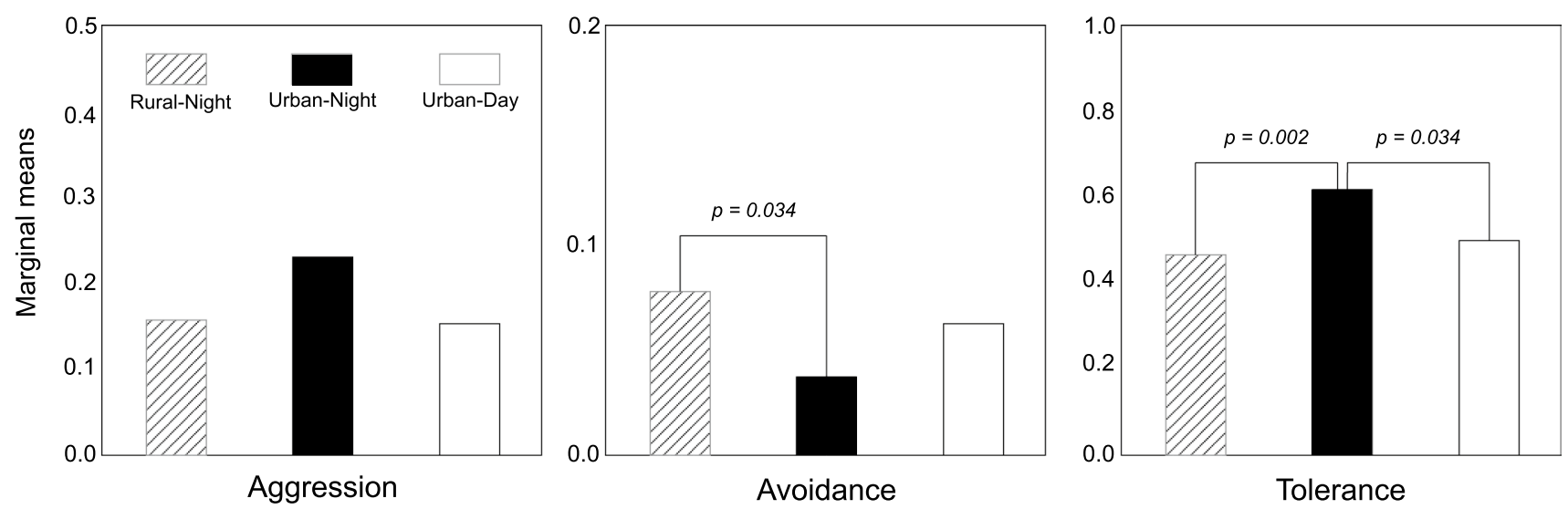

Fig. 3 Probability of the frequency of aggression, avoidance, and tolerance in the rural and urban populations of A. agrarius and pairwise comparison carried out with the use of the least significant difference test 
during nighttime in sites with low density. In this case, the rural population was characterized by significantly lower frequency of aggression than the urban population $(p=0.015)$.

The escape behavior differed significantly between the urban and rural populations and between the time of day (for whole model: $\chi^{2}=14.7, d f=3, p=0.002$, for intercept: Wald $\chi^{2}=50.9, d f=1, p=0.000$, for site and time of encounters: Wald $\chi^{2}=13.1, d f=2, p=0.001$, for density: Wald $\chi^{2}=1.7$, $d f=1, p=0.197)$. Compared with the urban population, the individual in the rural population that was the first to find the food (the first to appear in the observation site) was less likely to run first upon a direct encounter (Fig. 4). Differences at the border of statistical significance were also observed in the urban population between night and daytime $(p=0.050$, Fig. 4$)$.

\section{Discussion}

We hypothesized that the behavior of A. agrarius from urban and rural populations during direct encounters would be different. However, we did not prejudge the nature of these differences, because various reactions were described in the literature, e.g. urban song sparrows Melospiza melodia or Cuban rock iguana Cyclura nubile increased aggression (Lacy and Martins 2003; Evans et al. 2010; Scales et al. 2011), while urban coyotes or coachwhip snakes may potentially show increased tolerance towards conspecifics (Atwood and Weeks 2003; Mitrovich et al. 2009). Our results have shown that the social behavior in the urban and rural populations of the species studied varies, but other factors are also important, e.g. the time of day when the social encounters occur.

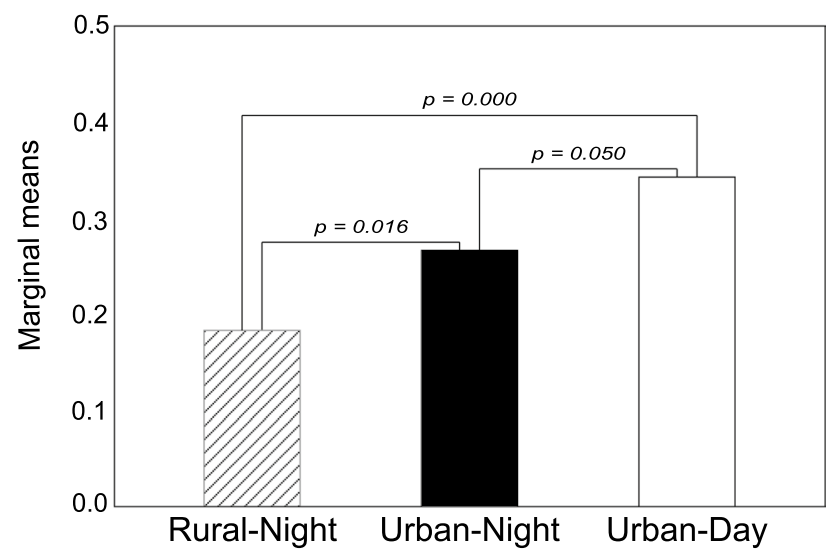

Fig. 4 Probability of the frequency of escape of the individual that was the first to find food (first to appear in the observation site) in relation to the site and time of encounters and pairwise comparison carried out with the use of the least significant difference test
The most basic difference observed in this study is that urban individuals are less likely to avoid close encounterswe recorded significantly more encounters in the urban area than in the rural area, more than we could expect based on the activity of the studied rodents (Fig. 2). The detailed analysis of the animal behavior additionally confirmed this finding - the encounters of the urban animals rarely ended with an immediate escape of one or both individuals compared to encounters of the rural animals (Fig. 3). However, more frequent encounters of urban animals do not translate into an increase in the frequency of aggression. In our study, we found a significant effect on aggressive behavior only in one case taking into account the interaction of several analyzed variables (Table 2): during nighttime, the rate of aggressive behavior in low-density sites was higher in the urban than rural sites. Given the methodological limitations of the camera-trap data, such results seem too weak and unsupported by other observations to formulate far-reaching conclusions about a greater level of aggression in social relations in urban areas in the case of A. agrarius.

The results showing the differences in the tolerance behavior are much more convincing. Comparison of the behavior of the urban and rural animals at night reveals a significantly higher level of tolerance behavior in the city. This is consistent with the hypothesis that individuals living in the city, forced to live at a higher density, should minimize the physiological costs of social interactions. Tolerance of the close presence of other individuals can be a way to mitigate energy costs of social interactions, because a high frequency of aggressive behavior would be associated with chronically elevated levels of stress hormones, which can be harmful to the animal (Korte et al. 2005; Bonier et al. 2007). Agonistic encounters can be also detrimental to animals through a greater incidence of physical injuries and increased disease transmission (Riley et al. 1998; Macdonald et al. 2004; Parker and Nilon 2008; Hurtado and Mabry 2017). Reacting with aggression to the close presence of other individuals is also costly in other ways, as it limits the foraging time. Therefore, tolerance of the close presence of another individual, even near the source of food, can be a favorable compromise. Such a compromise is easier to accept for urban animals, because anthropogenic food, which is an important part of their diet, is often available ad libitum (Babińska-Werka 1981; Chavez-Zichinelli et al. 2013). Higher body weight in urban animals (Andrzejewski et al. 1978; Łopucki et al. 2013) or lower stress levels (French et al. 2008; Lodjak and Maegi 2014; Łopucki et al. 2019) may, therefore, also be a result of more tolerant social behavior.

Additional data on the relationships between the individuals were provided by the analysis of the escape behavior during aggression and avoidance encounters. Such behavior can be interpreted in the context of the theory of monopolizing 
resources (Marty et al. 2019a,b). This monopolization can be expressed by a direct fight in defense or for access to the resource or by avoidance of confrontation. In the present study, the bait, i.e. anthropogenic food, which is an attractive in winter conditions, was a resource-related object of competition. For rodents from the rural population, the appearance of such food is an unusual situation; hence, they should be more strongly motivated to defend it against conspecifics. If this is the case, an individual that was the first to find the food source should be less likely to give way to a competitor appearing later (it should be more motivated to defend the valuable resource). For urban individuals, the appearance of portions of anthropogenic food is a potentially common situation (Babińska-Werka 1981; Chavez-Zichinelli et al. 2013; Thomas et al. 2018). Therefore, such food is not an extremely valuable resource, and it can be expected that the urban animal will be less determined to defend it. Our results seem to confirm this interpretation and show that the escape behavior and the tendency towards monopolization of resources can be useful indicators showing behavioral differences in relation to urbanization.

Our results also showed interesting differences between the behavior of the rodents during the day and night. The rural mice were active only at night, while the representatives of the urban population extended their period of activity to daytime. Urban animals use daytime hours for foraging because these hours are more thermally favorable in winter, while the pressure of natural predators in the city is lower (for details see Łopucki and Kiersztyn 2020). Our behavioral observations, however, provide insight into this issue and indicate that daily activity is associated with a different set of social behaviors, which largely resembles the behavior of rural animals: during the day, urban rodents are more likely to avoid each other, are less tolerant, and show aggression at the same level as their rural counterparts (Fig. 3). It is possible that such atavistic (characteristic of non-urban populations) behavior is associated with the perception of a higher predation risk during the day due to better visibility and higher noise pollution. It has been demonstrated in many papers that light is perceived by rodents as an indirect cue of predation risk and thus influences their behavior (Clarke 1983; Kotler 1984; Brillhart and Kaufman 1991; Shapira et al. 2013; Farnworth et al. 2016). It is also known that continuous anthropogenic noise can increase vigilance in animals, as it masks other signals from the environment (Dukas 2004; Rabin et al. 2006; Barber et al. 2010; Kern and Radford 2016). The higher vigilance (caused by lighting or noise) sensitizes small mammals to sudden appearance of another individual and more often causes an escape response. All these observations indicate that the plasticity of the social behavior of urban animals may be wider than usually described and depends on e.g. their daily activity. This shows how much research still needs to be done to determine to what extent the behavior of urban adapters is only a makeshift (stopgap) to evolve more sustainable solutions that facilitate the functioning of urban populations.

\section{Conclusions}

We found that urbanization affects the social behavior of A. agrarius. In the case of the studied species, an increase in tolerance rather than aggression in social relationships is the behavioral adaptation to urban life. Urban animals showed more tolerance behavior and had a lower tendency toward monopolization of food sources than rural mice. The behavior of urban animals, however, varies depending on the time of day: during the day, urban rodents are more likely to avoid each other, are less tolerant, and show aggression at the same level as their rural counterparts. We hypothesize that such atavistic behavior of urban animals during the day is associated with the perception of a higher predation risk due to better visibility and higher noise pollution. Our results open an avenue for formulating and verifying new hypotheses about the social behavior of urban populations.

Acknowledgements We would like to thank the anonymous reviewers for their suggestions that improved the quality of the paper.

\section{Compliance with ethical standards}

Conflict of interest On behalf of all authors, the corresponding author states that there is no conflict of interest.

Open Access This article is licensed under a Creative Commons Attribution 4.0 International License, which permits use, sharing, adaptation, distribution and reproduction in any medium or format, as long as you give appropriate credit to the original author(s) and the source, provide a link to the Creative Commons licence, and indicate if changes were made. The images or other third party material in this article are included in the article's Creative Commons licence, unless indicated otherwise in a credit line to the material. If material is not included in the article's Creative Commons licence and your intended use is not permitted by statutory regulation or exceeds the permitted use, you will need to obtain permission directly from the copyright holder. To view a copy of this licence, visit http://creativecommons.org/licenses/by/4.0/.

\section{References}

Andrzejewski R, Babińska-Werka J, Gliwicz J, Goszczyński J (1978) Synurbization process in population of Apodemus agrarius. I. Characteristics of populations in urbanization gradient. Acta Theriol 23:341-358

Atwell JW, Cardoso GC, Whittaker DJ, Campbell-Nelson S et al (2012) Boldness behavior and stress physiology in a novel urban environment suggest rapid correlated evolutionary adaptation. Behav Ecol 23:960-969 
Atwood TC, Weeks HP Jr (2003) Spatial home-range overlap and temporal interaction in eastern coyotes: the influence of pair types and fragmentation. Can J Zool 81:1589-1597

Aviles-Rodriguez K, Kolbe JJ (2019) Escape in the city: urbanization alters the escape behavior of Anolis lizards. Urban Ecosyst 22:733-742

Babińska-Werka J (1981) Food of the striped field mouse in different types of urban green areas. Acta Theriol 26:285-299

Barber JR, Crooks KR, Fristrup KM (2010) The costs of chronic noise exposure for terrestrial organisms. TREE 25:180-189

Bateman PW, Fleming PA (2014) Does human pedestrian behaviour influence risk assessment in a successful mammal urban adapter? J Zool 294:93-98

Baxter-Gilbert JH, Whiting MJ (2019) Street fighters: Bite force, injury rates, and density of urban Australian water dragons (Intellagama lesueurii). Austral Ecol 44:255-264

Becker DJ, Hall RJ (2014) Too much of a good thing: resource provisioning alters infectious disease dynamics in wildlife. Biol Lett 10:20140309

Bonier F (2012) Hormones in the city: endocrine ecology of urban birds. Horm Behav 61:763-772

Bonier F, Martin PR, Sheldon KS et al (2007) Sex-specific consequences of life in the city. Behav Ecol 18:121-129

Brillhart D, Kaufman D (1991) Influence of illumination and surface structure on space use by prairie deer mice (Peromyscus maniculatus bairdii). J Mamm 72:764-768

Cavalli M, Baladron AV, Isacch JP, Biondi LM, Bo MS (2018) The role of habituation in the adjustment to urban life: an experimental approach with burrowing owls. Behav Process 157:250-255

Chavez-Zichinelli CA, MacGregor-Fors I, Quesada J et al (2013) How stressed are birds in an urbanizing landscape? Relationships between the physiology of birds and three levels of habitat alteration. Condor 115:84-92

Clarke JA (1983) Moonlight's influence on predator-prey interactions between short-eared owls (Asio flammeus) and deermice (Peromyscus maniculatus). Behav Ecol Sociobiol 13:205-209

Contesse P, Hegglin D, Gloor S et al (2004) The diet of urban foxes (Vulpes vulpes) and the availability of anthropogenic food in the city of Zurich, Switzerland. Mamm Biol 69:81-95

del Barco-Trillo J (2018) Shyer and larger bird species show more reduced fear of humans when living in urban environments. Biol Lett 14:20170730

Dukas R (2004) Causes and consequences of limited attention. Brain Behav Evol 63:197-210

Evans J, Boudreau K, Hyman J (2010) Behavioural syndromes in urban and rural populations of song sparrows. Ethology 116:588-595

Farnworth B, Innes J, Waas JR (2016) Converting predation cues into conservation tools: the effect of light on mouse foraging behaviour. PLoS ONE 11:e0145432

Fernández-Juricic E, Schroeder N (2003) Do variations in scanning behavior affect tolerance to human disturbance? Appl Anim Behav Sci 84:219-234

Fokidis HB, Orchinik M, Deviche P (2011) Context-specific territorial behavior in urban birds: no evidence for involvement of testosterone or corticosterone. Horm Behav 59:133-143

Francis RA, Chadwick MA (2012) What makes a species synurbic? Appl Geogr 32:514-521

Francis MJ, Spooner PG, Matthews A (2015) The influence of urban encroachment on squirrel gliders (Petaurus norfolcensis): effects of road density, light and noise pollution. Wildl Res 42:324-333

French SS, Fokidis HB, Moore MC (2008) Variation in stress and innate immunity in the tree lizard (Urosaurus ornatus) across an urbanrural gradient. J Comp Physiol B 178:997-1005

Gallo T, Fidino M, Lehrer EW, Magle S (2019) Urbanization alters predator avoidance behaviors. J Anim Ecol 88:793-803
Gaynor KM, Hojnowski CE, Carter NH, Brashares JS (2018) The influence of human disturbance on wildlife nocturnality. Science 360:1232-1235

George SL, Crooks KR (2006) Recreation and large mammal activity in an urban nature reserve. Biol Conserv 133:107-117

Gortat T, Barkowska M, Gryczynska-Siemiatkowska A, Pieniążek A et al (2014) The effects of urbanization-small mammal communities in a gradient of human pressure in Warsaw city, Poland. Pol J Ecol 62:163-172

Hurtado G, Mabry KE (2017) Aggression and boldness in Merriam's kangaroo rat: an urban-tolerant species? J Mamm 98:410-418

Kern JM, Radford AN (2016) Anthropogenic noise disrupts use of vocal information about predation risk. Environ Pollut 218:988-995

Korte SM, Koolhaas JM, Wingfield JC, McEwen BS (2005) The Darwinian concept of stress: benefits of allostasis and costs of allostatic load and the trade-offs in health and disease. Neurosci Biobehav Rev 29:3-38

Kotler BP (1984) Effects of illumination on the rate of resource harvesting in a community of desert rodents. Am Midl Nat 111:383-389

Lacy KE, Martins EP (2003) The effect of anthropogenic habitat usage on the social behaviour of a vulnerable species, Cyclura nubila. Anim Conserv 6:3-9

Lodjak J, Maegi M (2014) Differences in nest site selection and baseline faecal corticosterone levels between urban and rural rooks (Corvus frugilegus). Hirundo 27:33-53

Łopucki R (2007) Social relationships in a bank vole Clethrionomys glareolus (Schreber, 1780) population: video monitoring under field conditions. Pol J Ecol 55:543-558

Łopucki R, Kiersztyn A (2020) The city changes the daily activity of urban adapters: camera-traps study of Apodemus agrarius behaviour and new approaches to data analysis. Ecol Indic 110:105957

Łopucki R, Mróz I, Berliński Ł, Burzych M (2013) Effects of urbanization on small-mammal communities and the population structure of synurbic species: an example of a medium-sized city. Can J Zool 91:554-561

Łopucki R, Klich D, Ścibior A, Gołębiowska D (2019) Hormonal adjustments to urban conditions: stress hormone levels in urban and rural populations of Apodemus agrarius. Urban Ecosyst 22:435-442

Łopucki R, Klich D, Kitowski I, Kiersztyn A (2020) Urban size effect on biodiversity: the need for a conceptual framework for the implementation of urban policy for small cities. Cities 98:102590

Lowry H, Lill A, Wong BBM (2013) Behavioural responses of wildlife to urban environments. Biol Rev 88:537-549

Macdonald DW, Harmsen BJ, Johnson PJ, Newman C (2004) Increasing frequency of bite wounds with increasing population density in Eurasian badgers, Meles meles. Anim Behav 67:745-751

Marty PR, Beisner B, Kaburu SSK et al (2019) Time constraints imposed by anthropogenic environments alter social behaviour in long-tailed macaques. Anim Behav 150:157-165

Marty PR, Balasubramaniam KN, Kaburu SSK et al (2019) Individuals in urban dwelling primate species face unequal benefits associated with living in an anthropogenic environment. Primates. https://doi. org/10.1007/s10329-019-00775-4

McKinney ML (2008) Effects of urbanization on species richness: a review of plants and animals. Urban Ecosyst 11:161-176

Meillere A, Brischoux F, Parenteau C et al (2015) Influence of urbanization on body size, condition, and physiology in an urban exploiter: a multi-component approach. PLoS ONE 10:e0135685

Mikula P, Šaffa G, Nelson E, Tryjanowski P (2018) Risk perception of vervet monkeys Chlorocebus pygerythrus to humans in urban and rural environments. Behav Process 147:21-27

Miranda AC, Schielzeth H, Sonntag T, Partecke J (2013) Urbanization and its effects on personality traits: a result of microevolution or phenotypic plasticity? Glob Change Biol 19:2634-2644 
Mitrovich MJ, Diffendorfer JE, Fisher RN (2009) Behavioral response of the Coachwhip (Masticophis flagellum) to habitat fragment size and isolation in an urban landscape. J Herpetol 43:646-656

Moiron M, González-Lagos C, Slabbekoorn H, Sol D (2015) Singing in the city: high song frequencies are no guarantee for urban success in birds. Behav Ecol 26:843-850

Møller AP (2012) Urban areas as refuges from predators and flight distance of prey. Behav Ecol 23:1030-1035

Oro D, Genovart M, Tavecchia G, Fowler MS, Martínez-Abraín A (2013) Ecological and evolutionary implications of food subsidies from humans. Ecol Lett 16:1501-1514

Palacio FX (2020) Urban exploiters have broader dietary niches than urban avoiders. Ibis 162:42-49

Parker TS, Nilon CH (2008) Gray squirrel density, habitat suitability, and behavior in urban parks. Urban Ecosyst 11:243-255

Podgórski T, Baś G, Jędrzejewska B, Sönnichsen L, Śnieżko S et al (2013) Spatiotemporal behavioral plasticity of wild boar (Sus scrofa) under contrasting conditions of human pressure: primeval forest and metropolitan area. J Mamm 94:109-119

Rabin LA, Coss RG, Owings DH (2006) The effects of wind turbines on antipredator behavior in California ground squirrels (Spermophilus beecheyi). Biol Conserv 131:410-420

Riley SPD, Hadidian J, Manski DA (1998) Population density, survival, and rabies in raccoons in an urban national park. Can J Zool 76:1153-1164

Santangelo JS, Rivkin LR, Johnson MTJ (2018) The evolution of city life. Proc Roy Soc B Biol Sci 285:e20181529

Scales J, Hyman J, Hughes M (2011) Behavioral syndromes break down in urban song sparrow populations. Ethology 117:887-895

Schell CJ, Young JK, Lonsdorf EV, Santymire RM, Mateo JM (2018) Parental habituation to human disturbance over time reduces fear of humans in coyote offspring. Ecol Evol 8:12965-12980

Shapira I, Walker E, Brunton DH, Raubenheimer D (2013) Responses to direct versus indirect cues of predation and competition in naive invasive mice: implications for management. NZ J Ecol 37:33-40

Solaro C, Sarasola JH (2019) Urban living predicts behavioural response in a neotropical raptor. Behav Process 169:103995
Sollmann R (2018) A gentle introduction to camera-trap data analysis. Afr J Ecol 56:740-749

Swaddle JP, Francis CD, Barber JR, Cooper CB et al (2015) A framework to assess evolutionary responses to anthropogenic light and sound. TREE 30:550-560

Thomas LS, Teich E, Dausmann K, Reher S, Turner JM (2018) Degree of urbanisation affects Eurasian red squirrel activity patterns. Hystrix It J Mamm 29:175-180

Tigas LA, Van Vuren DH, Sauvajot RM (2002) Behavioral responses of bobcats and coyotes to habitat fragmentation and corridors in an urban environment. Biol Conserv 108:299-306

Tryjanowski P, Møller AP, Morelli F, Biaduń W et al (2016) Urbanization affects neophilia and risk-taking at bird-feeders. Sci Rep 6:28575

Tuomainen U, Candolin U (2011) Behavioural responses to humaninduced environmental change. Biol Rev Camb Philos Soc 86:640-657

Uchida K, Suzuki KK, Shimamoto T, Yanagawa H, Koizumi I (2019) Decreased vigilance or habituation to humans? Mechanisms on increased boldness in urban animals. Behav Ecol. https://doi. org/10.1093/beheco/arz117

Vincze E, Papp S, Preiszner B et al (2016) Habituation to human disturbance is faster in urban than rural house sparrows. Behav Ecol 27:1304-1313

Weaver M, Hutton P, McGraw KJ (2019) Urban house finches (Haemorhous mexicanus) are less averse to novel noises, but not other novel environmental stimuli, than rural birds. Behaviour 156:1393-1417

Publisher's Note Springer Nature remains neutral with regard to jurisdictional claims in published maps and institutional affiliations. 